\title{
EFFECTIVE RESOURCE ESTIMATES FOR PRIMARY DIAMOND DEPOSITS FROM THE EKATI DIAMOND MINETM , CANADA
}

\author{
Darren Dyck ${ }^{1}$, Peter Oshust ${ }^{1}$, Jon Carlson ${ }^{1}$, Tom Nowicki ${ }^{2}$, and Matt Mullins ${ }^{3}$ \\ ${ }^{1}$ BHP Billiton Diamonds Inc., Kelowna, Canada $;{ }^{2}$ Mineral Services Canada Inc., Vancouver, Canada; ${ }^{3}$ BHP Billiton, \\ Johannesburg, South Africa
}

\section{INTRODUCTION}

The recent discovery and mining of the Ekati kimberlite pipes provides a useful example of a geological evaluation and resource estimation process for primary economic diamond deposits. The Ekati Diamond Mine is a joint venture between BHP Billiton (operator, $80 \%$ ) and the two original prospectors involved in its discovery (Chuck Fipke and Stewart Blusson). The Ekati property is situated in the Lac de Gras kimberlite field in the eastcentral portion of the Slave Province.

The first kimberlite (Point Lake) at Lac de Gras was discovered in 1991. Two years later in 1993, the Panda kimberlite was drill confirmed and five years later, in 1998, became the primary source of ore feed at the opening of the Ekati Diamond Mine ${ }^{\mathrm{TM}}$ (Ekati). The original process plant throughput was designed at 9,000 tonnes per day and kimberlite was mined from the Panda open pit as a single source until 2002. Currently, a blended stream of ore is processed from open pit operations at Panda, Misery and Koala as well as an underground operation at Koala North. Several other kimberlite pipes are at various stages of economic evaluation.

Between 1991 and 1996, exploration on the 344,000 ha property resulted in the discovery of numerous pipes including eight potentially economic kimberlites each requiring resource evaluation, i.e.: Panda, Misery, Koala, Koala North, Fox, Beartooth, Sable and Pigeon. Although these deposits have certain similar features to kimberlites in other provinces, the Ekati kimberlites exhibit several key differences that require special resource evaluation considerations.

\section{DATA SOURCES}

The isolated setting, the presence of abundant small lakes, and severe winter conditions make drilling an expensive but cost effective choice relative to other target testing methods. Nevertheless, two of the kimberlites (Fox and Panda) have also been bulk tested using underground declines to provide larger diamond parcels (up to several thousand carats) for value estimation and for assessing grade variance with sample size.
Consequently, the Ekati resource models are largely based on data from a combination of small diameter (NQ, HQ) diamond drill core and large diameter ( $\sim 0.15$ to $0.75 \mathrm{~m})$ reverse circulation (RC) drilling. Several hundred kilometers of drill holes have been completed at Ekati with the associated data managed by using a central oneto-many shared diamond resource database.

\section{GEOLOGY MODEL}

Within the Ekati area, the kimberlites are generally Eocene to Late Cretaceous in age (Creaser et al. 2003, Proceedings of the 8th International Kimberlite Conference) and intruded Archean age granitoid, metasedimentary and metavolcanic rocks. These occurrences are largely dominated by complex packages of resedimented and primary crater facies volcaniclastic kimberlite (RVK and PVK, respectively) to vertical depths of over 450 to 500 metres. Diatreme and hypabyssal kimberlite facies are less important as a resource at Ekati. Rare, probable diatreme facies kimberlite has only been recognized at the Fox kimberlite where it occurs beneath a thick zone of RVK. Magmatic kimberlite occurs in a sharp cross-cutting relationship below RVK at Pigeon. A geological review of the Ekati kimberlites is presented by Nowicki et al. (2003, Proceedings of the $8^{\text {th }}$ International Kimberlite Conference).

The first step in the resource modeling process is the generation of a wire-frame model of the kimberlite pipe "shell" based on geophysical data and contact pierce points of surveyed drill holes. Example pipe models, illustrating the wide range in shape and degree of complexity of the Ekati kimberlites are given in Figure 1. 


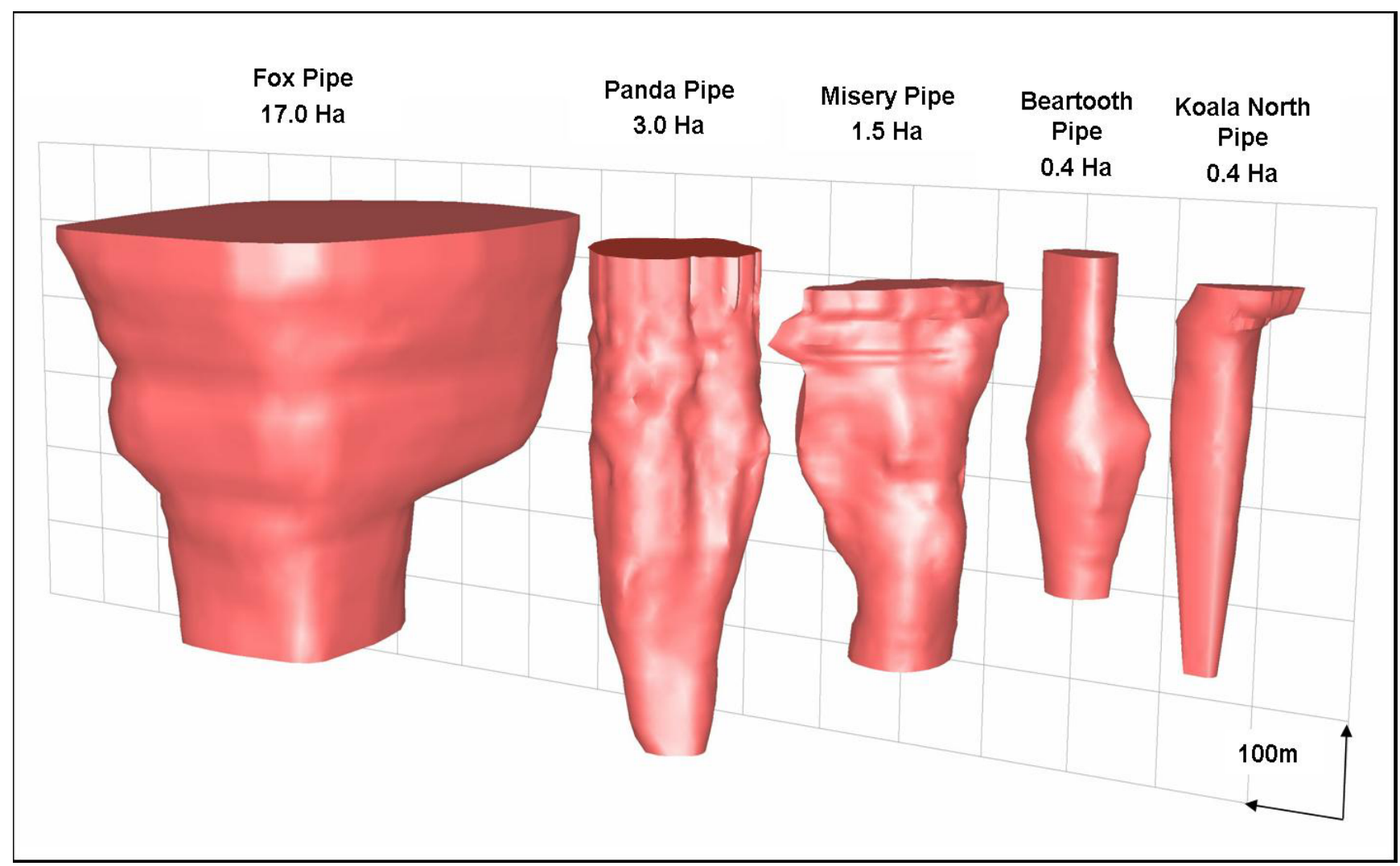

Figure 1: Solid-rendered wire-frame models of five economic kimberlite pipes at Ekati exhibiting the range of sizes and shapes observed in the intrusions.

The kimberlites generally form small, steep-sided (generally less than $5 \mathrm{ha}$ ) pipes that exhibit forms ranging from a simple carrot shape such as Koala North to complex examples with subsurface flaring and overhanging wall-rock contacts such as Beartooth. Deviation from circular shape in plan view is most often the result of local structural controls. At the Sable kimberlite the pipe walls dip outwards from the upper part of the body resulting in an initial increase in size with depth. Many of the pipes exhibit walls that are structurally controlled and flaring at the base of the RVK phases in the Fox and Pigeon pipes has been demonstrated by drilling.

Following construction of the pipe shell, it is necessary to construct internal geological or domain models of each kimberlite. Internal domains are defined where necessary to account for significant changes in either density or grade characteristics or both. These are generally, although not always, directly related to geological variations or phase changes observed in drill intersections and underground excavation. Thus the domains are typically modeled on the basis of the geological drill logs. As an example, the Koala pipe displays a well developed series of sub horizontal kimberlite phases of varying thickness, each with very distinct lithological, density and grade characteristics (Figure 2). In contrast, several pipes comprise a complex mixture of resedimented volcaniclastic material that, based on available drill information, cannot be reliably subdivided into lithologically distinct, continuous phases. For the purpose of resource modelling, these kimberlites are typically modeled as a single, internally complex geological domain. 


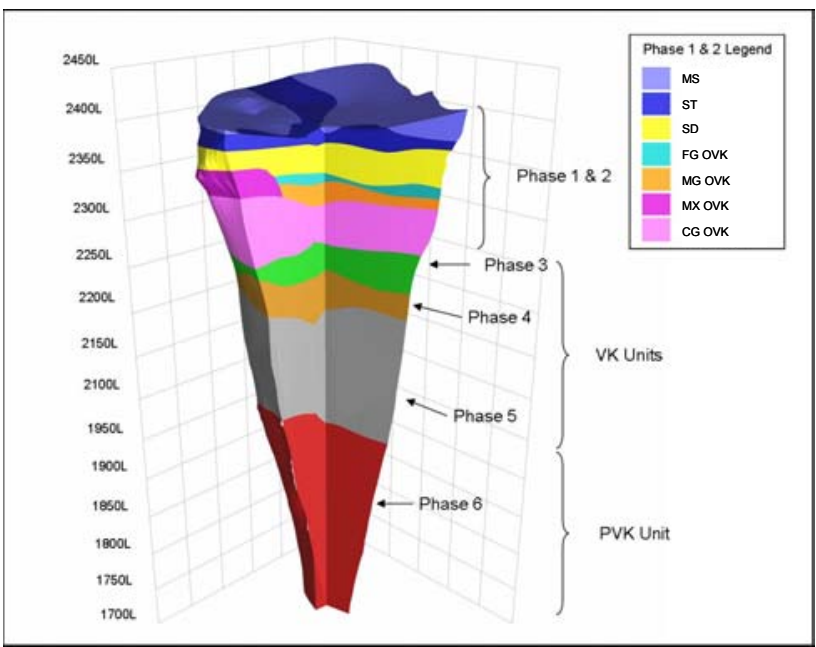

Figure 2: Cut-away view of the solid-rendered wire-frame model of the Koala pipe illustrating sub horizontal lithological domains.

Domains of waste kimberlite (uneconomic) and wall-rock megaxenoliths large enough to be model as selected waste units are rare at Ekati suggesting: 1) efficient excavation of country rock during emplacement; 2) limited spalling of wall-rock blocks following eruption; and 3) infilling of pipes primarily with relatively coarse-grained, juvenilerich kimberlitic material with relatively minor deposition of fine-grained material by low-energy sedimentation processes. Examples of waste domains are the stratified kimberlitic mudstone, siltstone and sandstone domains within the upper portions of the Koala pipe and the subhorizontal horizon of large granodiorite blocks in the upper portion of the tuffistic kimberlite zone at Fox.

\section{DENSITY MODEL}

Density models are created from drill core sample density data. The density data reside in the same database as the previously described drillhole data and wire-frame geological domain models. The laboratory method for determining the dry bulk density of kimberlite core samples was refined by independent study to provide consistent results specifically for the volcaniclastic kimberlite encountered at Ekati. This is characterized by low degrees of compaction and significant proportions of mud, fine-grained ash, alteration minerals and swelling clay which can result in samples that slake easily when immersed in water. Density determinations have been attempted on RC cuttings of kimberlite, but data produced were excluded from modeling due to bias introduced by the ash and silt sized material being lost during drilling and sample collection.

The density of the waste rock geology was modeled with a suite of at least 50 to a maximum of 200 density determinations to provide a reliable mean density value. For example, a model density of 2.73 dry metric tonnes per $\mathrm{m}^{3}$ is used for the granodiorite surrounding the PandaKoala-Fox kimberlite cluster.

Density models for kimberlite domains are more complex and several different approaches have been implemented at Ekati. These are largely driven by the internal lithological complexity of the kimberlite but take into consideration the minimum size of the selected mining unit (block) for which a confident tonnage forecast is required. For kimberlitic lithologies that are relatively homogeneous (e.g. mudstones, siltstones, sandstones, volcaniclastic varieties of uniform olivine content, and magmatic kimberlite) mean densities are typically based on a minimum of 50 declustered samples within the domain.

Burial and compaction of volcaniclastic kimberlite results in a systematic and significant increase in density with depth in the pipe (Figure 3). Thus, where a geological phase extends over a wide depth interval, it is necessary to subdivide it further into horizontal density domains. Geostatistics has also been successful in providing local density estimates where variogram models can be fitted to the data.

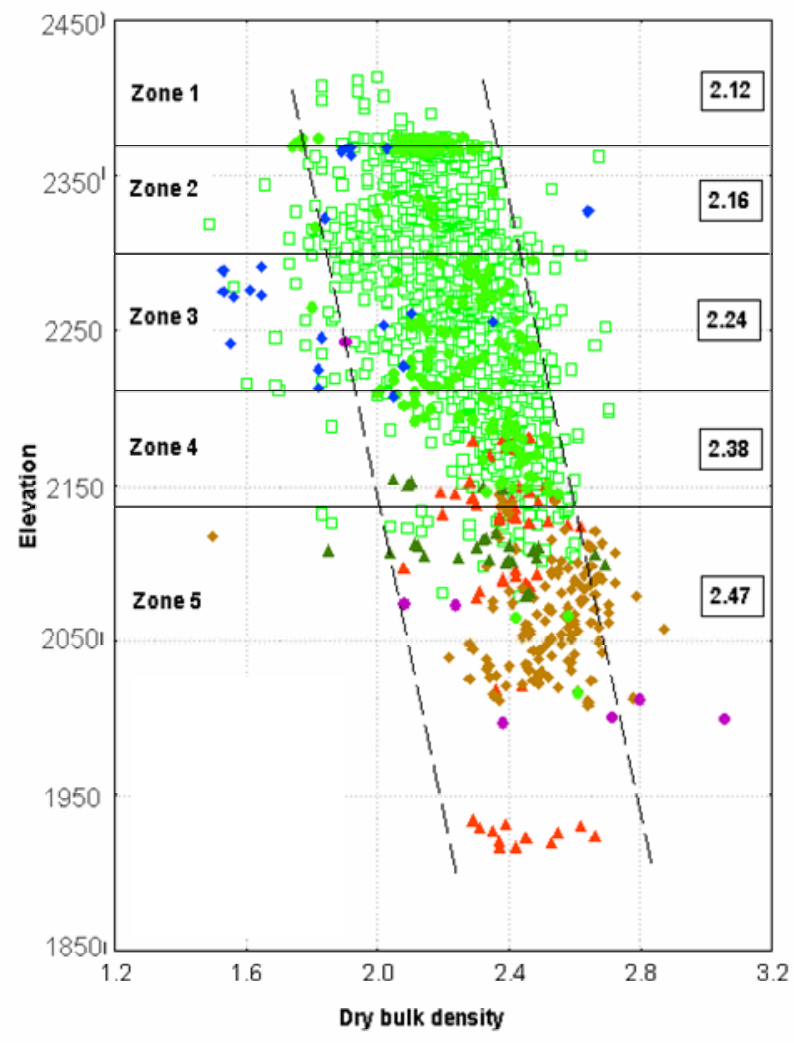

Figure 3: Scatterplot of bulk density sample values plotted versus elevation within the pipe. 


\section{GRADE MODEL}

Generally, diamonds occur in-situ in concentrations on average of 0.9 carats per tonne (cpt). Approximately 16,000 carats in total have been recovered from 36 pipes that have been bulk sampled to date. Virtually all of the coarse diamonds and representative populations of the smaller size diamonds have been individually characterized and the data captured in a relational diamond database. As with other world-wide localities, bulk sampled Ekati pipes exhibit significant differences in overall diamond grade, size distribution and properties (e.g., shape, colour and inclusions) indicating variable sampling of upper mantle diamond sources that occurred over time in the Lac de Gras (Gurney, 1998, per. comm.) as well as complex emplacement and resedimentation processes resulting in variable degrees of mixing, dilution and concentration of diamonds. Independent of this, emplacement processes of pipe excavation, brecciation and entrapment of host and cover rock xenoliths, and vent filling (primary and secondary) processes can mix, dilute and concentrate diamonds into unique populations of size, abundance, and quality.

Drilling large diameter RC holes with composited (on $30 \mathrm{~m}$ intervals) down-hole samples provides samples that are large enough in volume to recover sufficient stone counts (stone density) per sample that are statically significant at the kimberlite geological domains diamond size distribution. Ultimate grid hole spacing is a function of the kimberlite domain with the highest local grade variance unique to each pipe. The resulting spatial distribution of samples in each pipe allows for horizontal and vertical investigations of grade variability. Underground drifting provided larger populations for diamond value modeling and provided a change of support sample set that validated assumptions in the approach to achieve local (block) grade estimates.

Ekati obtains diamond grade data from an on-site 40 tonne per hour sample plant with a Sortex and grease table recovery circuit The differences in scale and processing parameters between the sample plant and the main process plant results in unequal diamond recoveries that are correlated using plant audit data and partition curves.

The resource grade is estimated at a base case of carats per tonne at an effective aperture size cut-off to account for bottom screen sizing inefficiencies that produce less than $100 \%$ diamond recovery in the fine diamond distribution tail. By convention, geological dilution is also included in the resource grade when selective mining is not possible. This base case allows the application and evaluation of mining and recovery techniques that optimize the minimum loss or dilution of the diamond population.

QA and QC for diamond sampling are important practices to generate useable high-quality data. To confirm the effectiveness diamond liberation between RC drill cuttings and blasted ore, both drill core and underground drifting has been sampled for comparative study of the effects of blasting and drilling on diamond liberation. Tracer diamond spiking has been employed effectively at studying diamond losses from the drilling collection system, plant recovery efficiency and sample crosscontamination. Also, consistent feedback and application of new technologies from each successive drill campaign over the last decade has improved the ability to drill consistently larger and deeper holes required for the inherently low grades of primary diamond deposits.

Given these parameters, the resource estimator relies on classical statistics and geostatistics to build an appropriate grade model for each geological domain that can be demarcated within a pipe.

Carats per tonne is the product of the stone density per tonne and carats per stone. Thurston (2001, per. comm.) has identified the strengths in using less variable stone density models when stone size variability affects the relatively high number of stones present per sample; however, stone size variability has not been observed within the domains modeled except for rare outliers of extremely large stones that require special attention regardless of methodology. To illustrate the variety of diamond densities in the Lac de Gras area, examples of bimodal, lognormal, and normal grade histograms from separate kimberlites are shown in Figure 4, 5 and 6 respectively.

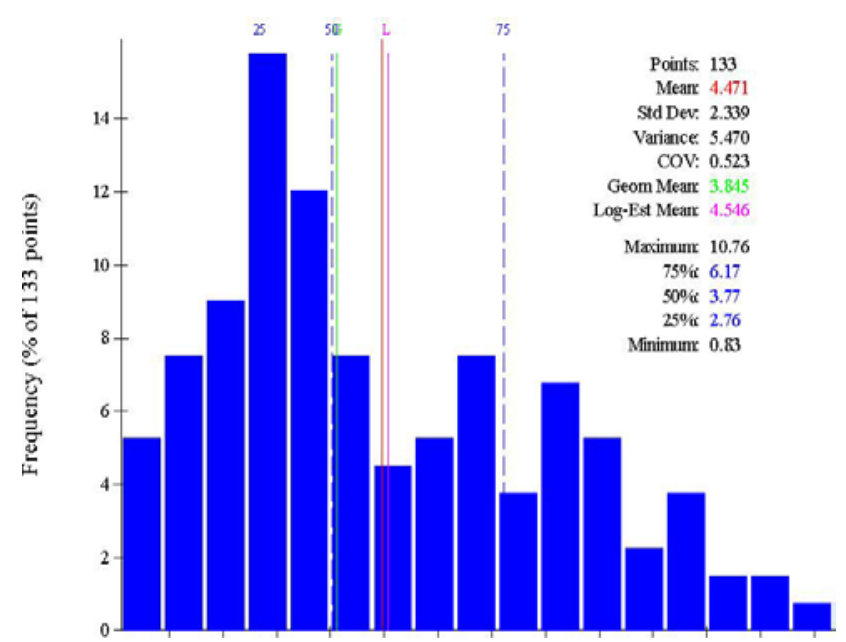

Figure 4: An example of a bimodal and possibly polymodal sample grade histogram from the Misery Pipe. Further subdomaining was required in this case. 


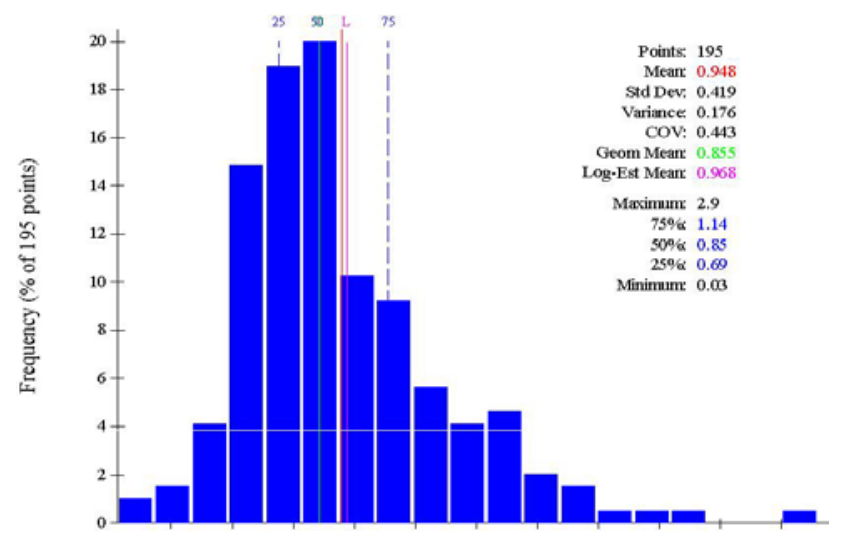

Figure 5: An example of a lognormal sample grade histogram from the Sable Pipe.

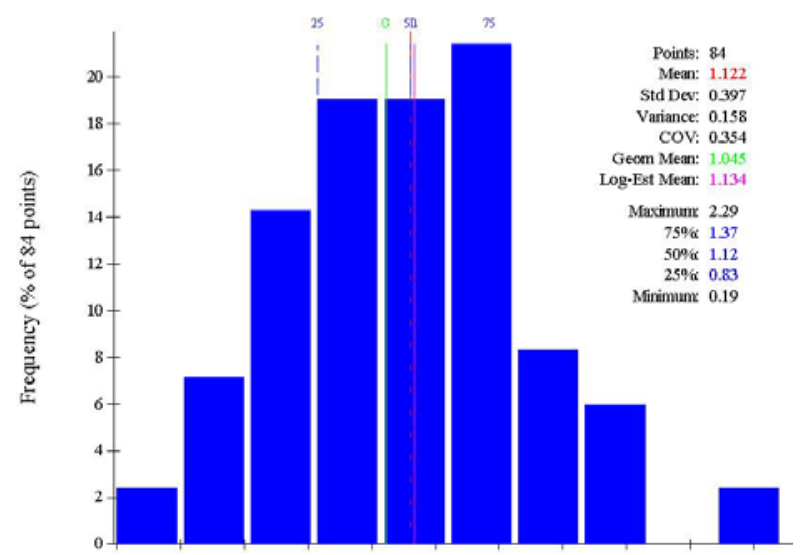

Figure 6: An example of a near normal sample grade distribution from the Beartooth Pipe.

Grade estimate methodologies applied to the data from these histograms from bulk sampled pipes at Ekati include:

- total grade as total carats from total tonnes sampled

- $\quad$ arithmetic mean of individual samples

- median

- geometric mean

- inverse distance polygonal method

- Sichel's t-estimator

- ordinary kriging of variograms

- Monte Carlo techniques

- conditional simulation (sequential gaussian) techniques

\section{CONCLUSION}

A kimberlite resource estimate is the product of a best-fit pipe volume model, an internal geological / density domain model and a grade model for each domain being assessed. Emplacement processes at Ekati have resulted in complex ore-bodies that vary considerably between kimberlite pipes. Thus, reliable construction of resource models requires careful assessment of factors affecting diamond distribution within each kimberlite and adaptation of sampling and estimation procedures to ensure that these are taken into account.

Mining is the ultimate test of the accuracy of a resource estimate since production can be reconciled against the deposit model to improve future iterations of estimates for the remaining resource base. Future areas of resource study at Ekati will focus on grade control sampling, selective mining of kimberlite ore with gradational internal ore waste boundaries,, conditional simulation and risk analysis.

\section{REFERENCES}

Creaser, R.A., Grütter, H., Carlson, J. and Crawford, B., 2003. Macrocrystal Phologopite Rb-Sr Dates for the Ekati Province Kimberlites, Slave Province, Canada: Evidence for Multiple Intrusive Episodes in the Paleocene and Eocene. Proceedings of the $8^{\text {th }}$ International Kimberlite Conference, Victoria, Canada, June 2003.

Nowicki, T.E., Dyck, D., Crawford, B., McElroy, R., Roebuck, S., Mustafa, J. and Carlson, J. 2003. A Review of the Kimberlite Pipes of the Ekati Property, Northwest Territories, Canada. Proceedings of the $8^{\text {th }}$ International Kimberlite Conference, Victoria, Canada, June 2003.

Contact: DR Dyck, 8-1699 Powick Road, Kelowna, BC, Canada, V1X 4L1, E-mail: Darren.R.Dyck@bhpbilliton.coma 